\section{Intergeneric Graft Compatibility within the Family Araliaceae}

\author{
Kenneth W. Leonhardt ${ }^{1}$
}

Additional index words. Aralia, G insing, Panax family, propagation

Summary. N ovelty Araliaceae potted plants were created by a wide variety of interspecific and intergeneric graft combinations. T wenty-four species of 10 genera were tested, of which 20 species of eight genera resulted in 85 graft combinations that grew. Intergeneric graft combinations with Schefflera arboricola included eight species in five other genera. I ntergeneric graft combinations with $x$ Fatshedera lize included 11 species in five other genera. Schefflera arboricola scions grew more vigorously on N othopanax and Polysaias rootstocks than on Schefflera rootstocks. The highest intergeneric graft compatibility scores for each genera included combinations with Schefflera. Plant propagation instructors may find these results useful in designing grafting exercises.

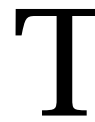

he Araliaceae is an important plant family in the commercial foliage plant industry. Species and cultivars of A ralia, x Fatshedera, Fatsia, H edera, Panax, Polyscias, Pseudopanax, Schefflera, and Tupidanthus are popular decorative plants for interior use. Plants commonly known in the trade as Brassaia actinophylla and D izygotheca elegantissima have been reclassified into Schefflera but retain the same species epithet (Lowry et al. 1989). Aralias are also popular for landscapes in areas with mild winters. "Ivy Trees" made by grafting cultivars of $\mathrm{H}$ eder a helix onto rootstocks of the intergeneric hybrid $x$

${ }^{1} \mathrm{D}$ epartment of $\mathrm{H}$ orticulture, $\mathrm{U}$ niversity of $\mathrm{H}$ awaii, 3190 Maile Way, H onolulu, H awaii 96822

The cost of publishing thispaper wasdefrayed in part by the payment of page charges. U nder postal regulations, this paper must behereby marked advertisement solely to indicate thisFact.
Fatshedera (Fatsia x H edera) that have been grown erect are sold as novelty specimens. G rowers usually get a high percentage of successful grafts with healthy plant material and good grafting technique.

Variegated forms of A ralia elata do not root from cuttings and produce nonvariegated seedlings. The variegated forms are propagated by budding onto seedling or vegetatively produced nonvariegated rootstocks of A . elata (L eiss, 1977). O ne variegated form of A. elata also has been cleftgrafted successfully onto a rootstock of A. spinosa (Raulston, 1985.)

The relative ease of the $H$ edera $x$ Fatshedera graft raised the possibility of graft compatibility of $\mathrm{H}$ edera with other relatives, particularly thosegrowing tall rapidly or having other desirable characteristics. Preliminary attempts to graft $\mathrm{H}$ edera onto Polyscias and Schefflera were promising. O ur study was undertaken to determine graft compatibility between other speciesand generain the A raliaceae and to determine if scion growth was affected by the choice of rootstock.

\section{M aterials and methods}

Twenty-three cultivars of A raliaceae representing six genera and 16 species were obtained from commercial sources. Two species each of two genera native to $\mathrm{H}$ awaii, $C$ heirodendron and Tetraplasandra, were collected in the Koolau Mountains on 0 ahu (Table 1 ).

Rootstocks propagated from tip cuttings rooted in equal parts vermiculite and perlite under intermittent mist and full sun were grown in $15-\mathrm{cm}$ plastic pots containing equal parts peat moss, perlite, and field soil (by volume). Lime and a slow-release granular fertilizer were incorporated. R ootstockswere established in agreenhouse under $25 \%$ shade cover until grafted.

A wide assortment of rootstockscion combinations were tested for interspecific and intergeneric compatibility. O ne-hundred and onetest combinations and seven control combinationsweretested. T welve cultivars (five genera, nine species) were used as rootstocks and 22 cultivars (six

Table 1. A raliacea cultivarsused in graft compati bi lity studies

\begin{tabular}{|c|c|c|c|}
\hline \multirow[b]{2}{*}{ G enus species } & \multirow[b]{2}{*}{ Variety or cultivar } & \multicolumn{2}{|c|}{ U sed as: } \\
\hline & & R ootstock & Scion \\
\hline \multirow[t]{2}{*}{ Cheirodendron sp. } & a & & $X$ \\
\hline & b & & $\mathrm{X}$ \\
\hline x Fatshedera lizéz & & $X$ & $x$ \\
\hline H edera helix & $\mathrm{H}$ ahn's & & $x$ \\
\hline N othopanax scuttelarius & & $X$ & \\
\hline Polysciasbalfouriana marginata & & & $x$ \\
\hline P. balfouriana & Pennockii ${ }^{2}$ & $X$ & $x$ \\
\hline P. filicifolia ${ }^{z}$ & & $x$ & $x$ \\
\hline P. filicifolia & Golden Prince ${ }^{z}$ & $x$ & $x$ \\
\hline P. fruticosa & Elegans & & $\mathrm{x}$ \\
\hline \multirow[t]{3}{*}{ P. guilfoylei } & Crispa ${ }^{2}$ & $x$ & $x$ \\
\hline & Quinquefolia & & $x$ \\
\hline & Variegata & $X$ & \\
\hline \multirow[t]{2}{*}{ P. guilfoylei victoriae } & & & $x$ \\
\hline & Variegata & & $x$ \\
\hline P. paniculata & Variegata & & $x$ \\
\hline Schefflera actinophylla & & $X$ & \\
\hline S. arboricola ${ }^{z}$ & & $x$ & $x$ \\
\hline S. arboricola & Variegata ${ }^{2}$ & $x$ & $x$ \\
\hline S. elegantissima & & & $x$ \\
\hline S. polybotrya & & $X$ & \\
\hline \multirow[t]{3}{*}{ S. sp. } & Big L eaf & & $X$ \\
\hline & M anila Ruffle & & $x$ \\
\hline & Star Shine & & $x$ \\
\hline \multicolumn{2}{|l|}{ Tetraplasandra kauaiensis } & & $x$ \\
\hline T. meiandra & & & $x$ \\
\hline T upi danthus calyptratus & & $X$ & \\
\hline
\end{tabular}

${ }^{2}$ Cultivars used as scions grafted onto the same cultivar to serve as controls for the benchmark compatibility rating of $4=$ vigorous sci on growth. 


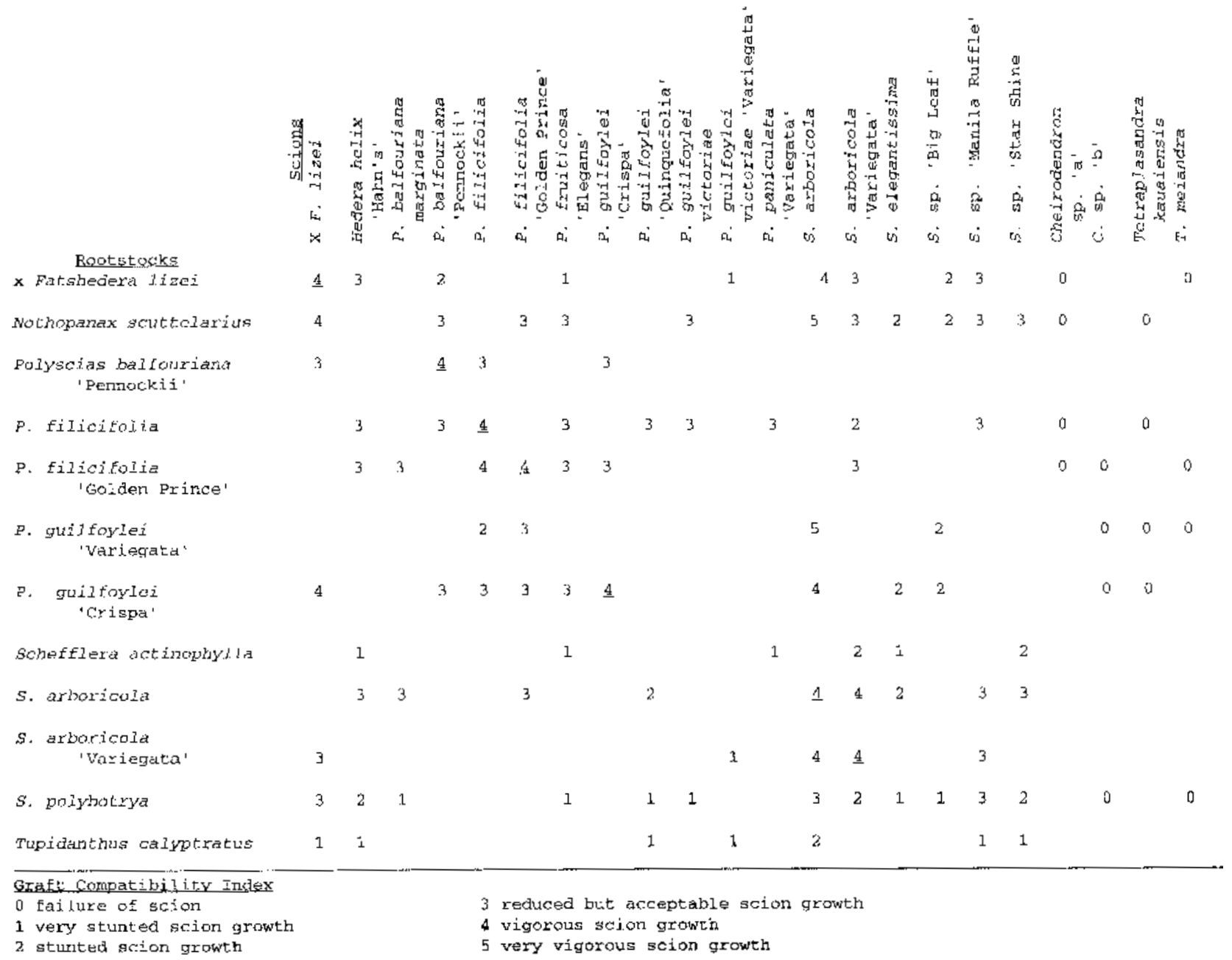

Fig. 1. Mean scored for rootstock-sci on compati bi lity for selected A raliaceae. Scores for control combi nati onsare underlinest- $A$

genera, 16 species) were selected as scions (Table 1 ). Side veneer grafts were used for $\mathrm{H}$ edera because of the small diameter of the scions. Cleft grafts were used when scions were much smaller in diameter than stocks. Standard whip and tongue grafts were used for all others ( $H$ artmann et al., 1990). Two to six replications were made of each graft combination. O ne or two small leaves or parts of leaves were retained on each scion. The graft unions were wrapped with raffia and sealed with an asphalt-based grafting compound. G rafted plants wereplaced under $73 \%$ shade for 2 to 4 weeks. When vegetative buds on the scions began to grow, plantswere transferred to full sun. The raffia was cut after 6 weeks to avoid girdling. Suckers that appeared on the rootstocks were re moved.

All replications of graft combinations were made on the same day and were evaluated 6 months later. A rating system based on scion growth $(0=$ failure of scion to $5=$ very vigorous scion growth) was used to assess graft combination compatibility. Seven cultivars of three genera were used as scions on their own rootstocks as a control. Their compatibility rating of 4 denotes vigorous scion growth ( $\mathrm{Fig}$. 1 ). Aesthetic appeal of combinations wasnot considered in evaluating compatibility of rootstocks and scions.

\section{R esults and Discussion}

Eighty-five graft combinations, including all combinations, except those involving a native $C$ hei rodendron or Tetraplasandra species, grew.

$\mathrm{N}$ othopanax and Polyscias proved to be suitable rootstocks for Polyscias and Schefflera scions. The hybrid genus $x$ Fatshedera also was a suitable rootstocks for Schefflera scions, but less suitable for Polysciasscions (T able 2). X Fatshedera also was a suitable rootstock for $\mathrm{H}$ edera, one of its parental genera.

Schefflera arboricola was a better
T able 2. Mean graft compati bi lity scores for Polyscias and Schefflera scions on four rootstock genra. The number of different test combinationsisin parentheses

\begin{tabular}{lll}
\hline Stocks/ scions & Polyscias & Schefflera \\
\hline x Fatshedera & $1.3(3)$ & $3.0(4)$ \\
N othopanax & $3.0(4)$ & $3.0(6)$ \\
Polyscias & $3.0(17)$ & $2.9(8)$ \\
Schefflera & $1.5(10)$ & $2.4(15)$ \\
M ean & $2.4(34)$ & $2.7(33)$ \\
\hline
\end{tabular}

rootstock than S. pol ybotrya for $\mathrm{H}$ edera, Polyscias, and Schefflera scions. Fourteen species or cultivars were grafted on S. polybotrya, but only x Fatshedera and two Schefflera species performed acceptably. Grafts of four cultivars of three Polysciasspecies on S. polybotrya resulted in very stunted scion growth, but each Polysci ascultivar grew acceptably when grafted onto $\mathrm{S}$. arboricola, $\mathrm{N}$ othopanax, or other Polyscias rootstocks (Fig. 1).

Six reciprocal graft combinations using three genera were made ( $T$ able 
Table 3. Performance of $\mathbf{s} x$ reci procal graft combinations.

\begin{tabular}{llcc}
\hline Stock & \multicolumn{1}{c}{ Scion } & $\begin{array}{c}\text { Compatibility } \\
\text { score }\end{array}$ & $\begin{array}{c}\text { Compatibility score } \\
\text { of reciprocal graft }\end{array}$ \\
\hline P. balfouriana 'Pennockii' & x F. lize & 3 & 2 \\
& P. filicifolia & 3 & 3 \\
& P. guilfoylei 'C rispa' & 3 & 3 \\
P. filicifolia 'Golden Prince' & P. guilfoylei 'C rispa' & 3 & 3 \\
S. arboricola 'Variegata' & X F. lize & 3 & 3 \\
& S. arboricola & 4 & 4 \\
\hline
\end{tabular}

Table 4. Summary of hi ghest intergeneri graft compati bi lity scoresase ther rootstocks, scion, or both.

\begin{tabular}{lcl}
\hline G enus & H ighest score & \multicolumn{1}{c}{ M ost compatible genera } \\
\hline Schefflera & 5 & N othopanax, Polyscias \\
N othopanax & 5 & Schefflera \\
Polyscias & 5 & Schefflera \\
x Fatshedera & 4 & N othopanax, Polyscias, Schefflera \\
H edera & 3 & x Fatshedera, Polyscias, Schefflera \\
Tupidanthus & 2 & Schefflera \\
Cheirodendron & 0 & None \\
Tetraplasandra & 0 & None \\
\hline
\end{tabular}

3). There were no appreciable differences among reciprocal grafts of five of the combinations, but the combination of $x$ Fatshedera lizei on Polyscias balfouriana 'Pennockii' resulted in a stronger union and better scion growth than the reciprocal combination.

Schefflera arboricola was unsurpassed as a scion and gave vigorous to very vigorous growth when grafted on its own variegated cultivar, $x$ Fatshedera, $\mathrm{N}$ othopanax, or Polyscias. It grew less vigorously on S. polybotrya and Tupidanthusbut wasequal to or better than other scions tested on these two rootstocks. When grafted onto $\mathrm{N}$ othopanax and $\mathrm{P}$. guilfoylei 'V ariegata', Schefflera arboricola grew morevigorously than on its own roots. This was the only example of a control combination outperformed by a test combination (Fig. 1).

Tupidanthuswasa poor rootstock for $\mathrm{H}$ edera, Polysci as and Schefflera. $X$ Fatshedera on Tupidanthus also resulted in very stunted scion growth.

All 16 combinations using four species of two $\mathrm{H}$ awaiian native genera of A raliaceae on $x$ Fatshedera, N othopanax, Polyscias, and Schefflera failed (Fig. 1). Theenvironmental conditions at a 2000-foot elevation where the $C$ heirodendron and Tetraplasandra scions were collected was quite different from the near sea-level greenhouse conditions in which they were tested and may have contributed to the failures.
These results indicate that a wide variety of intergeneric graft combinations are possible in the Araliaceae. Table 4 lists the genera tested, the highest intergeneric graft compatibility score achieved as either rootstock or scion, and the genera combined for that score. The highest intergeneric graft compatibility scores achieved for each genera included combinations with Schefflera.

This information on graft compatibility within some A raliaceae may be useful to nurserymen in creating novelty potted plants for decorative use. The ready compatibility and ease of grafting for many combinationsalso may be useful in designing grafting exercises for propagation classes.

\section{Literature Cited}

H artman, H.T., D.E. K ester, and F.T. Davies. 1990. Plant propagation pinciples and practices. 5th ed. Prentice $\mathrm{H}$ all, Englewood Cliffs, N.J.

Leiss J. 1977. Propagation of Aralia elata 'Variegata'. Proc. Intl. Plant Prop. Soc. 27:461-463.

Lowry, P.P., J.S. Miller, and D.G. Frodin. 1989. $\mathrm{N}$ ew combinationsand namechanges for some cultivated tropical O Id World and Pacific Araliaceae. Baileya 23(1):5-13.

$R$ aulston, J .C. 1985. T en outstanding flowering trees for potential southeastern U.S. Production. Proc. Intl. Plant Prop. Soc. 35:723-728. 